\title{
JURNAL
}

\section{Simulasi Sistem Keamanan Jaringan Komputer Berbasis IPS Snort dan Honeypot Artilery}

\author{
Alja Aminanto ${ }^{1}$, Wiwin Sulistyo ${ }^{2}$ \\ ${ }^{1,2}$ Fakultas Teknologi Informasi Universitas Kristen Satya Wacana \\ Jl. Dr. O. Notohamidjojo 1-10, Salatiga 50711, Indonesia \\ Email :1672015235@student.uksw.edu, ${ }^{2}$ wiwinsulistyo@uksw.edu
}

\begin{abstract}
The Intrusion Prevention System (IPS) Snort is a server security System that can prevent attacks by examining and recording all data packets as well as recognizing packets with sensors, when the attack has been identified, IPS Snort will deny the access (block) and log of all data packets identified. However by using only IPS Snort which can only check and note the Allert attacks that are incoming in less sense to secure a server by collaborating with the other server's secure system in the sense of being able to make the network security of the server better. Honeypot Artillery chosen which works when there is a Hacker trying to penetrate through open ports can be detected as if hackers can break through the system, then Honeypot Artillery will provide information about who attackers and how the attacker could enter the Snort IPS system for later record in the database that can be viewed on the Web interface, Allert recorded on the experiment that has been done in the database as much as 9453 on TCP protocol as much as 9\%, UDP as much as < 1\%, and ICMP As much as $91 \%$.
\end{abstract}

Keywords: IPS, Snort, Honeypot Artillery

\begin{abstract}
Abstrak
IPS (Intrusion Prevention System) Snort merupakan sistem keamanan server yang dapat mencegah serangan dengan memeriksa dan mencatat semua paket data serta mengenali paket dengan sensor, disaat serangan telah teridentifikasi, IPS Snort akan menolak akses (block) dan mencatat $(\log )$ semua paket data yang teridentifikasi tersebut. Namun dengan hanya menggunakan IPS Snort yang hanya dapat memeriksa dan mencatat Allert serangan yang masuk dirasa kurang untuk mengamankan sebuah server dengan mengkolaborasikan dengan sistem keaman server yang lain dirasa dapat membuat kemanan jaringan server menjadi lebih baik. Dipilihlah Honeypot Artillery yang berfungsi ketika ada Hacker mencoba melakukan penetrasi melalui port yang terbuka maka dapat terdeteksi seolah olah Hacker dapat menembus sistem, lalu Honeypot Artillery akan memberikan informasi tentang siapa penyerang dan bagaimana penyerang bisa masuk ke sistem Snort IPS untuk kemudian dicatat di database yang dapat dilihat di web interface, Allert yang tercatat pada percobaan yang telah dilakukan di database sebanyak 9453 pada protokol TCP sebanyak $9 \%$, UDP sebanyak $<1 \%$, dan ICMP sebanyak $91 \%$.
\end{abstract}

Kata kunci: IPS, Snort, Honeypot Artillery 


\section{Pendahuluan}

Ancaman siber kini mempunyai spektrum yang sangat lebar, salah satu ancaman terbesar adalah malware. Sebagai contoh adalah serangan malware ransomware yang pernah mengakibatkan dua rumah sakit di Indonesia lumpuh. Dalam laporan tahunan Honeynet Project tahun 2018, jumlah total serangan yang menyerang Indonesia pada 21 sensor yang telah terpasang yaitu sebanyak 12.895.554 serangan, dengan jumlah serangan malware sebanyak 513.863 serangan[1]. Berkaca pada kasus tersebut dibutuhkan sistem maupun perangkat yang mumpuni dalam mendeteksi serta malacak serangan-serangan siber, dengan begitu sistem jaringan server perlu dilengkapi dengan adanya sistem keamanan yang memadai sehingga mampu mendeteksi aktifitas yang mencurigakan agar bisa diambil tindakan yang sesuai. Salah satunya menggunkan sistem IPS (Intrusion Prevention System) Snort yang dapat mencegah serangan dengan memeriksa dan mencatat semua paket data serta mengenali paket dengan sensor, disaat serangan telah teridentifikasi, IPS Snort akan menolak akses (block) dan mencatat (log) semua paket data yang teridentifikasi tersebut. Namun dengan hanya menggunakan IPS Snort yang hanya dapat memeriksa dan mencatat Allert serangan yang masuk dirasa kurang untuk mengamankan sebuah server dan belum cukup untuk menahan, dan melakukan respon balik yang tepat kepada attacker pada sebuah jaringan komputer. Maka dari itu kelemahan Snort IPS yang ada akan dicoba untuk diminimalisir dengan mengkolaborasikan dengan sistem keaman server yang lain. Dipilihlah Honeypot Artillery yang berfungsi ketika ada Hacker mencoba masuk melalui port yang terbuka maka dapat terdeteksi lalu Honeypot Artillery akan memberikan informasi tentang siapa penyerang dan bagaimana penyerang bisa masuk ke sistem Snort IPS untuk kemudian dicatat di database yang dapat dilihat di web interface.

Mengacu pada latar belakang yang ada maka dilakukan penelitian yang bertujuan untuk menerapkan sistem keamanan jaringan berbasis Intrusion Prevention System (IPS) menggunakan snort dan Honeypot Artillery, bisa membantu administrator jaringan dalam mengamankan sistem jaringan (lokal / internet) yang digunakan dari ancaman pencurian dan perusakan data serta dapat mengetahui jenis - jenis serangan yang mengancam sistem.

\section{Tinjuan Pustaka}

Penelitian sebelumnya yang menjadi acuan berjudul " Rancang Bangun Snort Base IPS "Intrusion Prevention Systems (IPS) merupakan sistem perangkat lunak, yang digunakan untuk mendeteksi ancaman yang terjadi di suatu jaringan atau sistem jaringan sebagai tindakan perlindungan data yang ada di dalam jaringan. Snort merupakan salah satu tools yang digunakan pada IPS yang berfungsi sebagai alert, sehingga snort menjadi tool pilihan dalam mengamankan jaringan komputer. 
AITI: Jurnal Teknologi Informasi

Volume 16 No. 2 Agustus 2019, 135-150

Pengaturan IPS pada snort perlu memperhatikan kondisi dan kebutuhan sistem jaringan pada studi kasus[2].

Menurut penelitan selanjutnya "Analisis dan Implementasi Honeypot Menggunakan Dionaea Sebagai Penunjang Keamanan Jaringan " Penelitian selanjutnya disarankan memperhatikan implementasi honeypot harus seimbang antara keamanan pada aspek jaringan dengan keamanan pada aspek sistem operasi, karena teknologi selalu berkembang maka tingkat keamanan sistem operasi selalu berkembang dan sistem operasi selalu diperbaharui. Disamping itu honeypot akan lebih baik lagi apabila dikombinasikan[3].

Intrusion Prevention System (IPS), adalah pendekatan yang sering digunakan untuk membangun sistem keamanan komputer. IPS mengkombinasikan teknik firewall dan metode Intrusion Detection System (IDS) dengan sangat baik. Teknologi ini dapat digunakan untuk mencegah serangan yang masuk ke jaringan lokal dengan memeriksa dan mencatat semua paket data serta mengenali paket dengan sensor, di saat serangan telah teridentifikasi, IPS menolak akses (block) dan mencatat (loging) semua paket data yang teridentifikasi tersebut. Jadi IPS bertindak sepeti layaknya firewall yang melakukan allow dan block yang dikombinasikan seperti IDS yang dapat mendeteksi paket secara detail. IPS menggunakan signatures untuk mendeteksi traffic di jaringan dan terminal, dimana pendeteksian paket yang masuk dan keluar (inbound-outbound) dapat dideteksi sedini mungkin sebelum merusak atau mendapatkan akses ke dalam jaringan lokal[4].

Snort merupakan salah satu tool pada IDS dengan komunitas opensource sehingga Snort menjadi tool pilihan dalam mengamankan jaringan komputer. Kemudahan memahami rules pada Snort dan kemudahan dalam membuat signature juga merupakan keunggulan yang dimiliki oleh Snort[5].

Honeypot adalah security resource yang yang sengaja dibuat untuk diselidiki, diserang, atau dikompromikan[6]. Honeypot merupakan suatu cara untuk membuat sistem palsu atau layanan palsu yang berfungsi untuk menjebak pengguna yang mempunyai tujuan buruk atau menangkal usaha-usaha yang dapat merugikan sistem atau layanan [7].

\section{Metode Penelitian}

Metode penelitian yang digunakan dalam penelitian ini adalah model PPDIOO (Prepare, Plan, Design, Implement, Operate, and Optimize )[8]. 


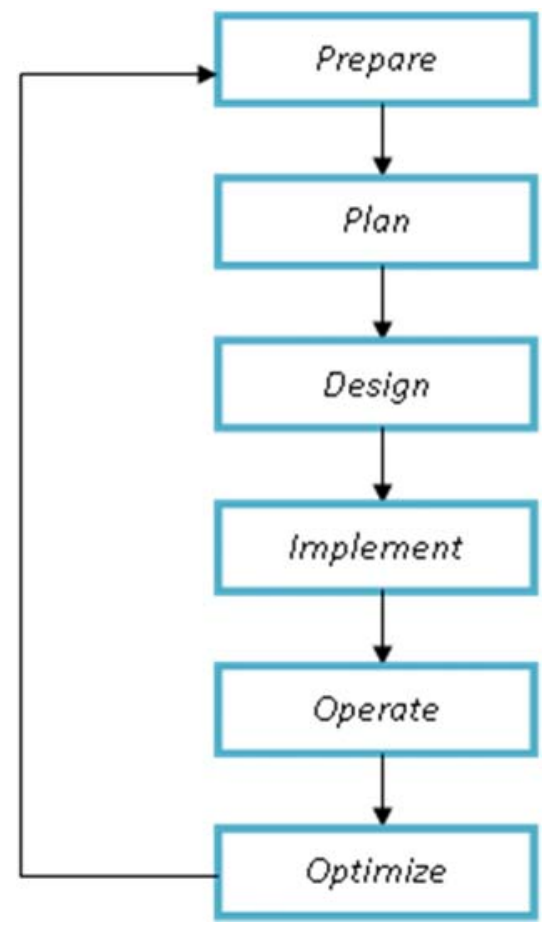

Gambar 1 Tahapan Penelitian

Model penelitian pada Gambar 1, dijelaskan sebagai berikut:

Tahap perencanaan (Plan) dilakukan dengan cara membaca jurnal dan refrensi yang telah dikumpulkan untuk mengtahui cara kerja dan kebutuhan sistem agar berjalan seperti yang diharapkan.Kemudian dilanjutkan ke tahap persiapan seperti memetakan kebutuhan sistem berupa software yang diperlukan untuk mendukung sistem tersebut. Pada tahap Perencanaan (prepare) ini bersamaan dengan tahap Persiapan (plan), dikarenakan antara persiapan dan perancangan keduanya saling berhubungan dan menjadi dasar yang harus diperhatikan. Sehingga tahap selanjutnya menjadi lebih terarah.

Tabel 1 berisi pemetaan Software atau perangkat lunak yang dibutuhkan untuk membangun sistem sebagai berikut:

Tabel 1 Pemetaan perangkat lunak

\begin{tabular}{llll}
\hline No & Jenis & Versi & Keterangan \\
\hline 1 & Ubuntu server & 19.04 & Sebagai OS server \\
2 & Snort & 2.9 .14 & Untuk mencatat Allerts yang masuk \\
3 & Acidbase & 1.4 .5 & Untuk mengecek alert jaringan \\
4 & Honeypot Artillery & 1.5 & Sistem keamanan yang diimplementasikan
\end{tabular}


AITI: Jurnal Teknologi Informasi

Volume 16 No. 2 Agustus 2019, 135-150

Hardware atau perangkat keras yang digunakan untuk membangun sistem adalah Laptop Toshiba Satellite L645 dengan spesifikasi processor Intel Core i5 dan RAM 4GB DDR3. Laptop tersebut digunakan sebagai development server.

Setelah persiapan hardware dan software selesai, selanjutnya masuk pada tahapan design. Design merupakan tahapan perancangan topologi jaringan yang digunakan.

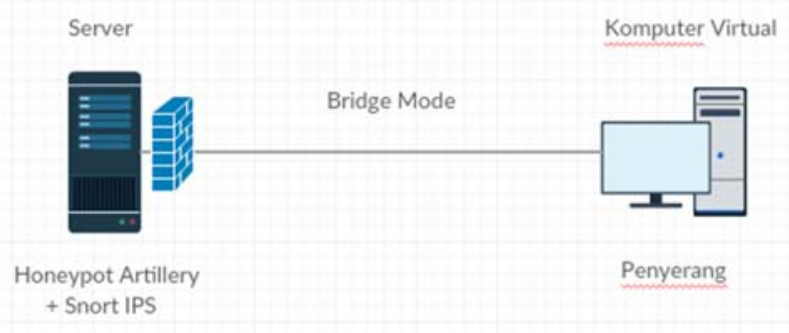

Gambar 2 RancanganTopologi Jaringan

Dalam pembuatan proyek akhir ini penulis menggunakan 1 buah laptop sebagai server dan software Virtual Box untuk komputer virtual yang digunakan sebagai client/penyerang, untuk penghubung antara server dan penyerang menggunakan mode Bridge. Server dikonfigurasi menggunakan Artillery dan Snort IPS sebagai sistem keamanan. Komputer virtual client/Penyerang digunakan untuk melakukan uji coba layanan dan uji coba sistem keamanan.

Tabel 2 Pengalamatan Perangkat

\begin{tabular}{lll}
\hline No & Perangkat & Alamat Perangkat \\
\hline 1 & Server & $192.168 .10 .5 / 24$ \\
\hline 2 & Client / Penyerang & $192.168 .10 .8 / 24$
\end{tabular}

\section{Hasil dan Pembahasan}

Fase Implementasi (Implement)"Simulasi Sistem Keamanan Jaringan Komputer Berbasis IPS Snort dan Honeypot Artilery" terbagi menjadi dua bagian, yaitu implementasi instalasi sistem keamanan Honeypot Artillery dan Snort IPS. 


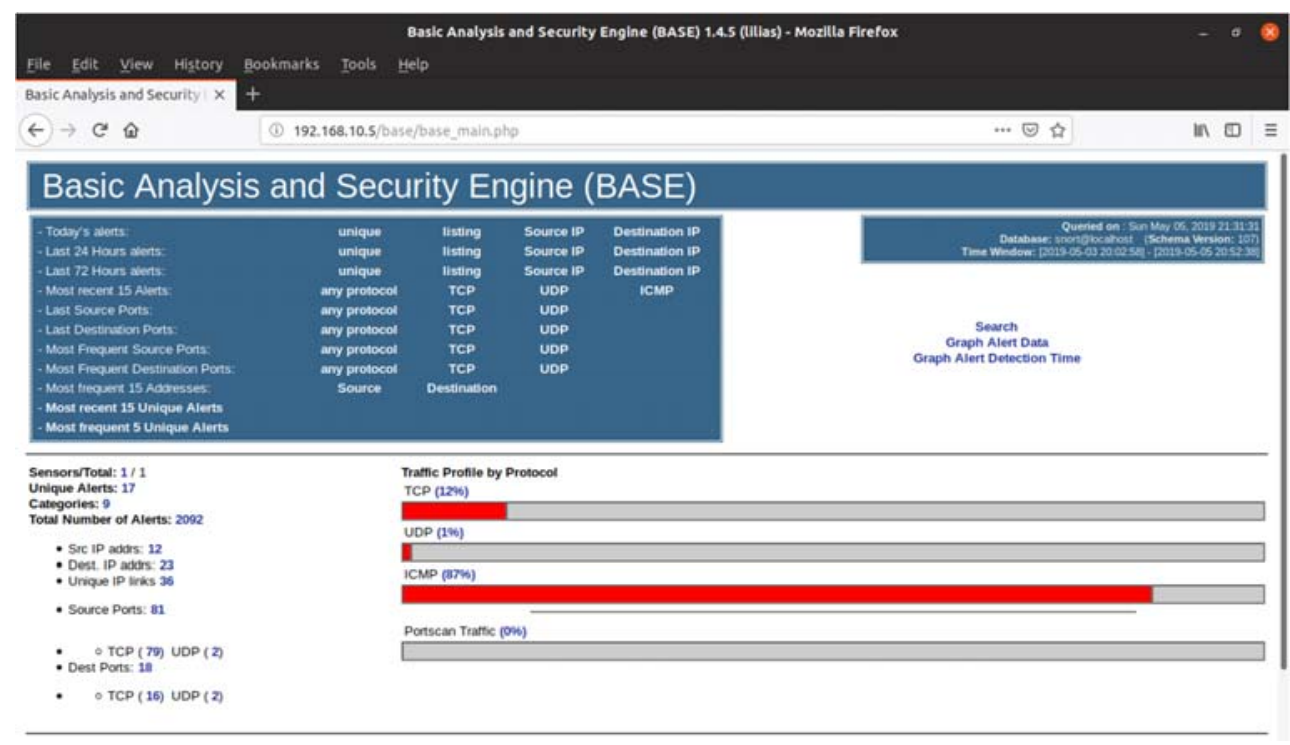

Gambar 4 tampilan Base Snort

Pada gambar 4 menunjukan instalasi Snort Base telah berhasil ditunjukkan dari Total Number of Alerts yang bertambah pada saat dilakukan test ping. Kemudian pada baris Traffic Profile by Protocol menujukan statistik serangan apa saja yang masuk di server.

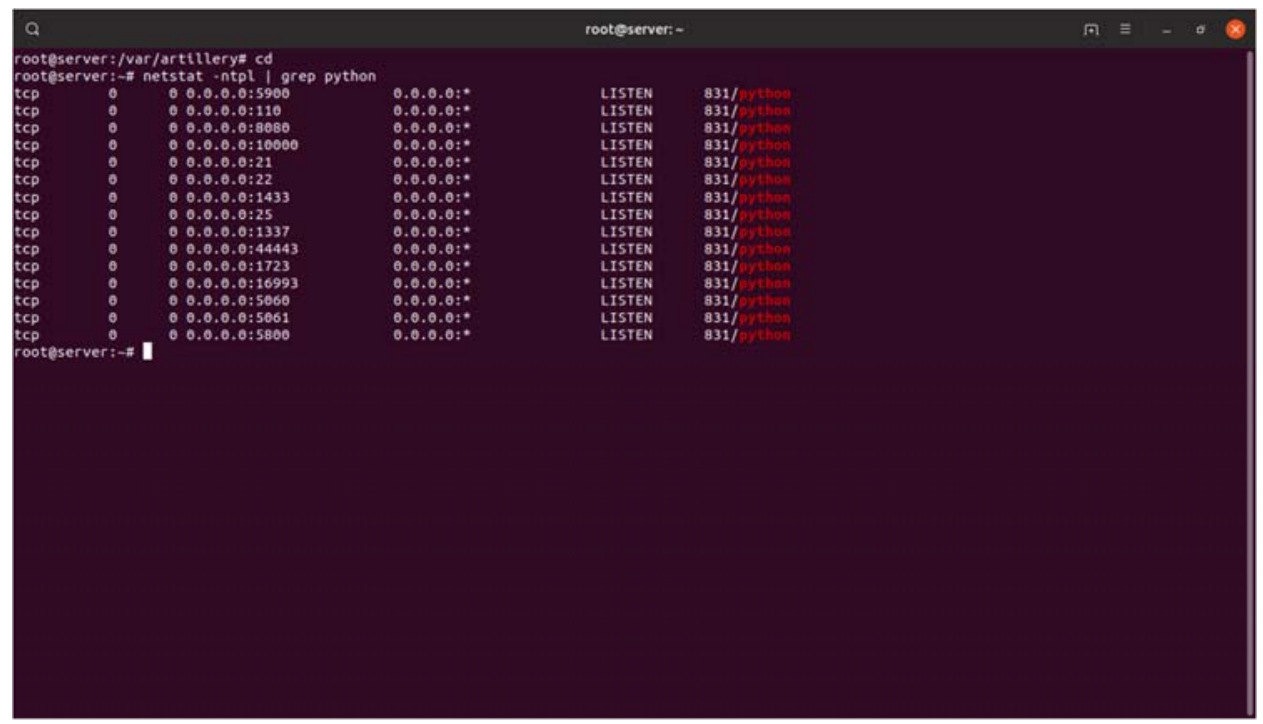

Gambar 5 port yang telah dikonfigurasi.

Gambar 5 menunjukan instalasi Honeypot Artillery telah berhasil ditunjukkan dengan port yang dikonfigurasi telah muncul seperti pada gambar $\mathbf{5}$. Maka konfigurasi port pada server menggunakan Honeypot Artillery telah berhasil dan siap untuk menangkap serangan yang masuk pada setiap port yang telah disetting. 
Skenario Fase Operate (Operasional) pengujian untuk Tugas Akhir "Simulasi Sistem Keamanan Jaringan Komputer Berbasis IPS Snort dan Honeypot Artilery" adalah sebagai berikut:

a. Administrator akan melakukan konfigurasi pada Honeypot Artillery untuk menentukan port yang akan diemulasi pada server.

b. Setelah Honeypot Artillery dikonfigurasi, Client/Penyerang akan melakukan koneksi ke server dan melakukan scanning menggunakan NMAP.

c. Setelah proses scanning, Client/Penyerang akan melakukan telnet ke port yang terbuka untuk mencoba masuk kedalam server.

d. Jika Client/Penyerang melakukan telnet ke port yang diemulasi oleh Honeypot Artillery, maka Client/Penyerang tersebut akan terkena larangan akses ke server dan terkena banned.

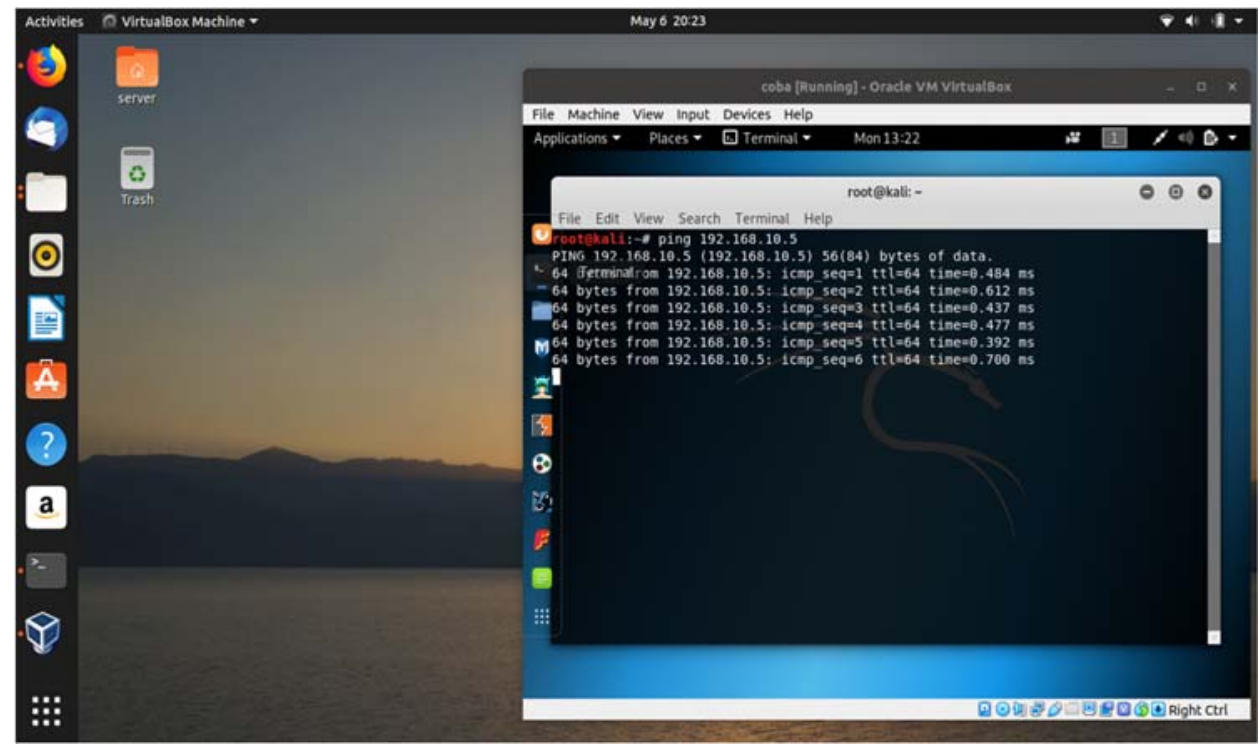

Gambar 6 koneksi ke server.

Pada gambar 6 Client/Penyerang melakukan koneksi ke server berupa test ping pada alamat IP server 192.168.10.5. 


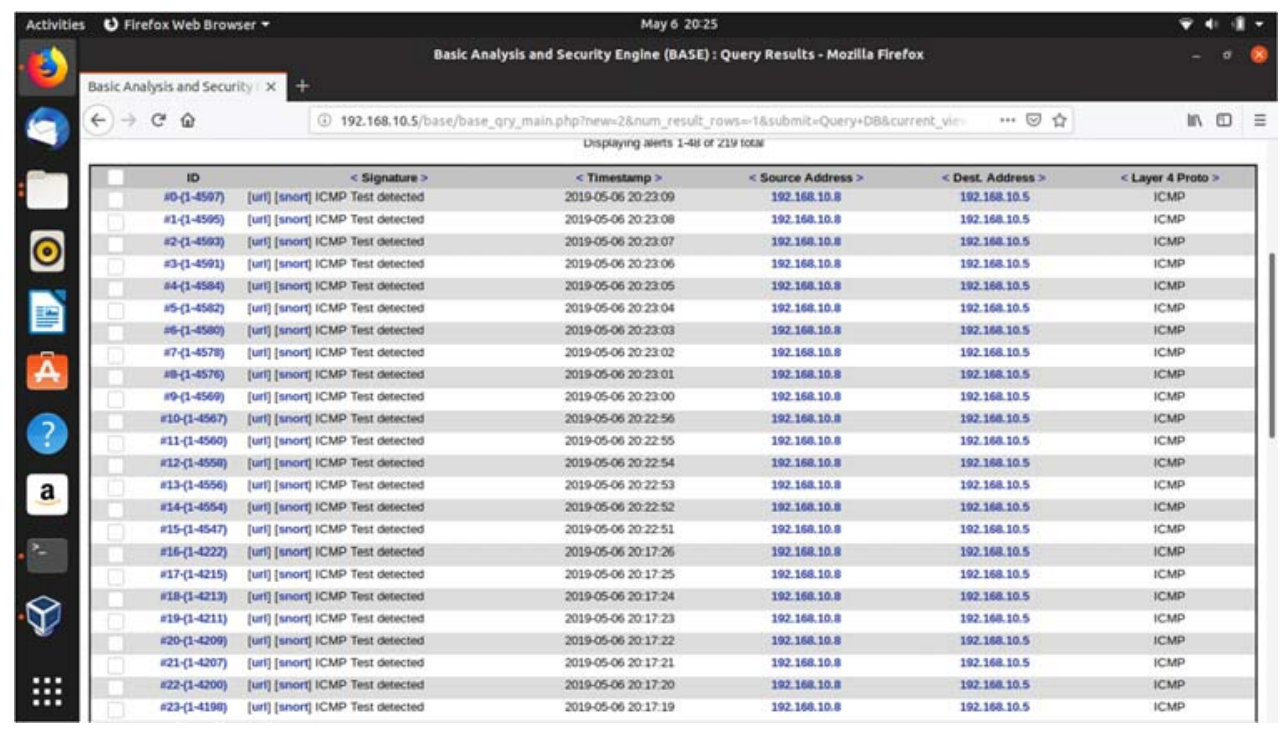

Gambar 7 hasil allert pada base snort.

Telihat pada gambar IP penyerang yaitu 192.168.10.8 yang tertulis pada baris Source Address mencoba melakukan koneksi ke server dengan IP 192.168.10.5 yang tertulis pada baris Dest. Address snort lansung merespon allert tersebut kemudian menampilakan di base snort.

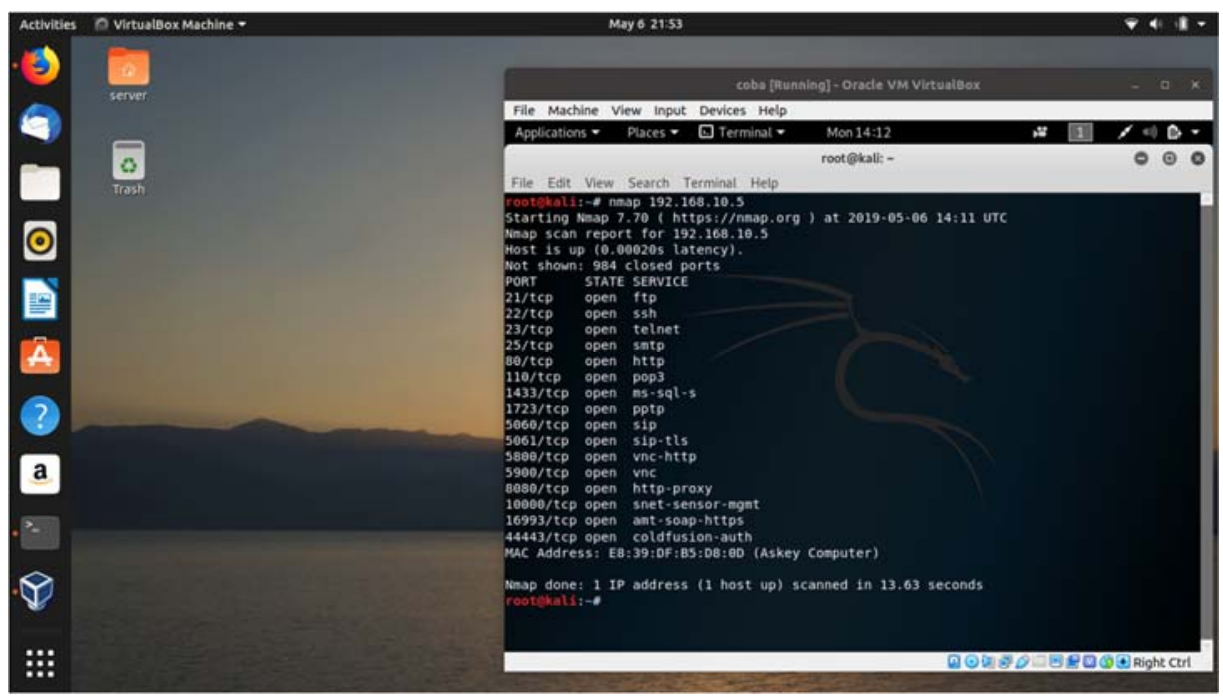

Gambar 8 Scanning port.

Pada gambar 8 User melakukan scanning port menggunakan aplikasi nmap untuk melihat port yang terbuka pada server. 
AITI: Jurnal Teknologi Informasi

Volume 16 No. 2 Agustus 2019, 135-150

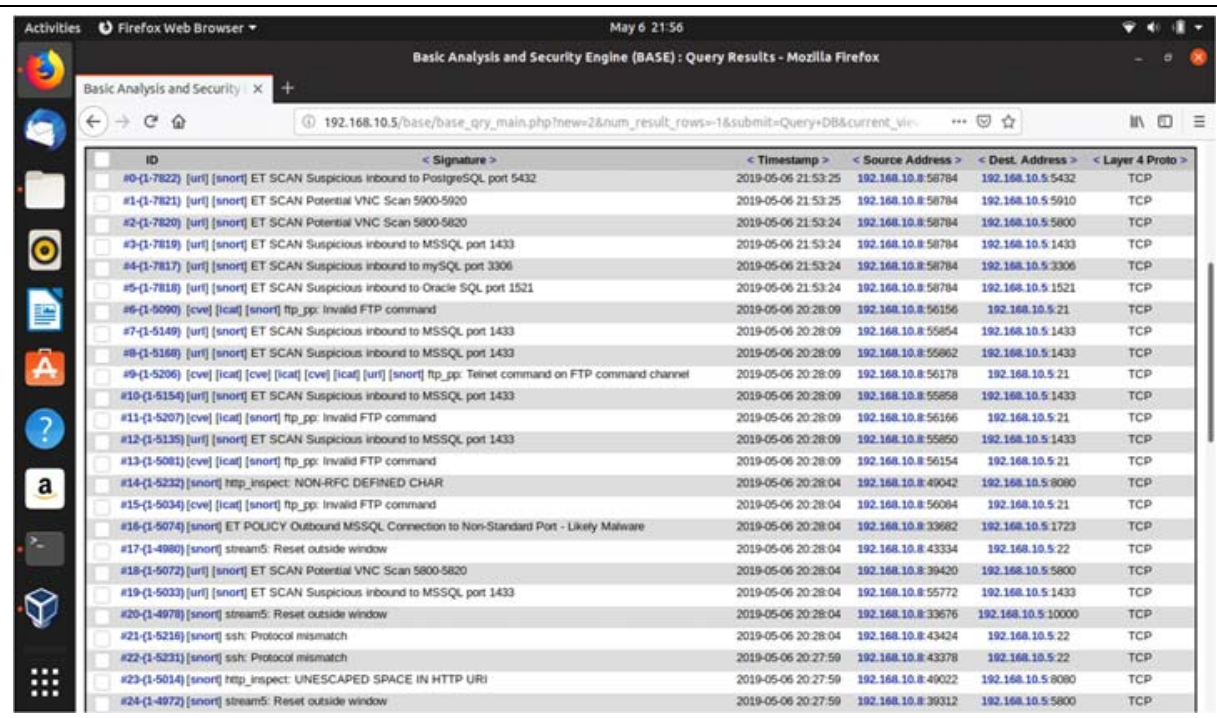

Gambar 9 Hasil allert Scanning port pada Base snort.

Gambar 9 menjelaskan snort base menangkap lagi aktifitas allert Scanning port yang dilakukan oleh Client/Penyerang.

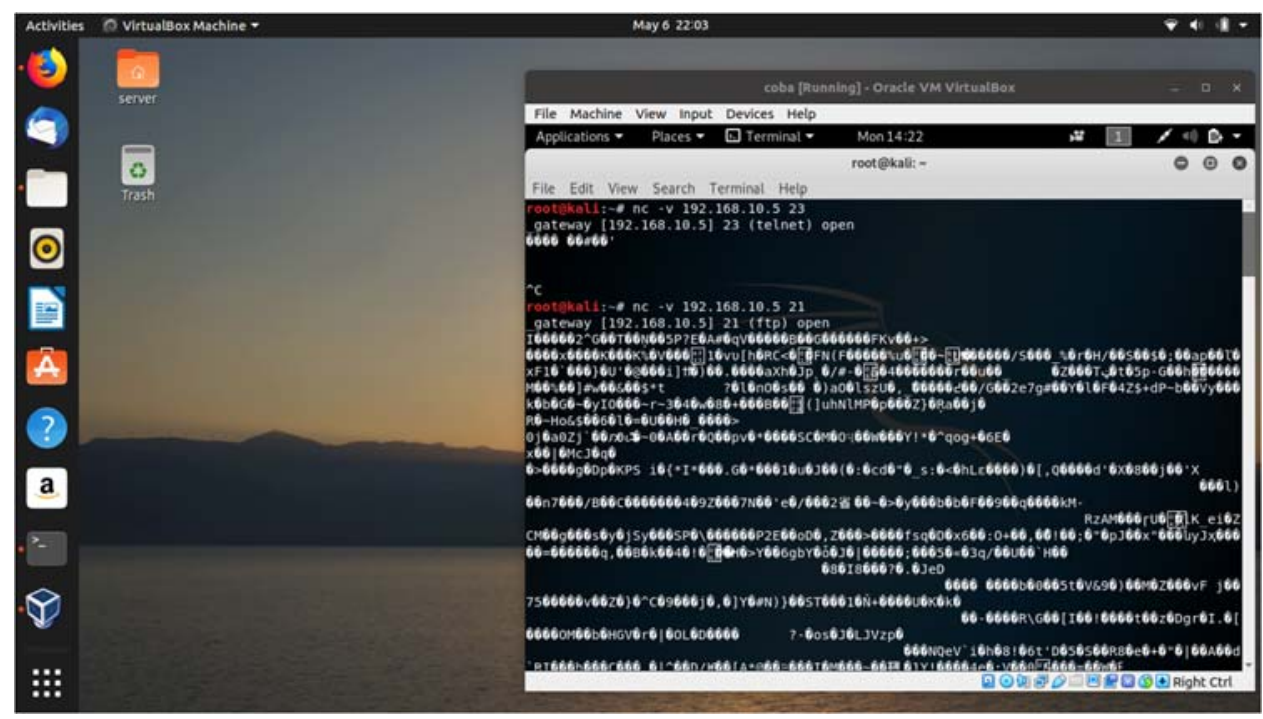

Gambar 10 Telnet Testing.

Client/Penyerang melakukan telnet pada server dengan tujuan IP dan port yang terbuka dari server. Beberapa port yang terbuka merupakan port yang diemulasi oleh Honeypot Artillery, Client/Penyerang akan melakukan telnet ke dua port tersebut untuk menguji sistem yang telah dikonfigurasi seperti pada gambar 10 . 


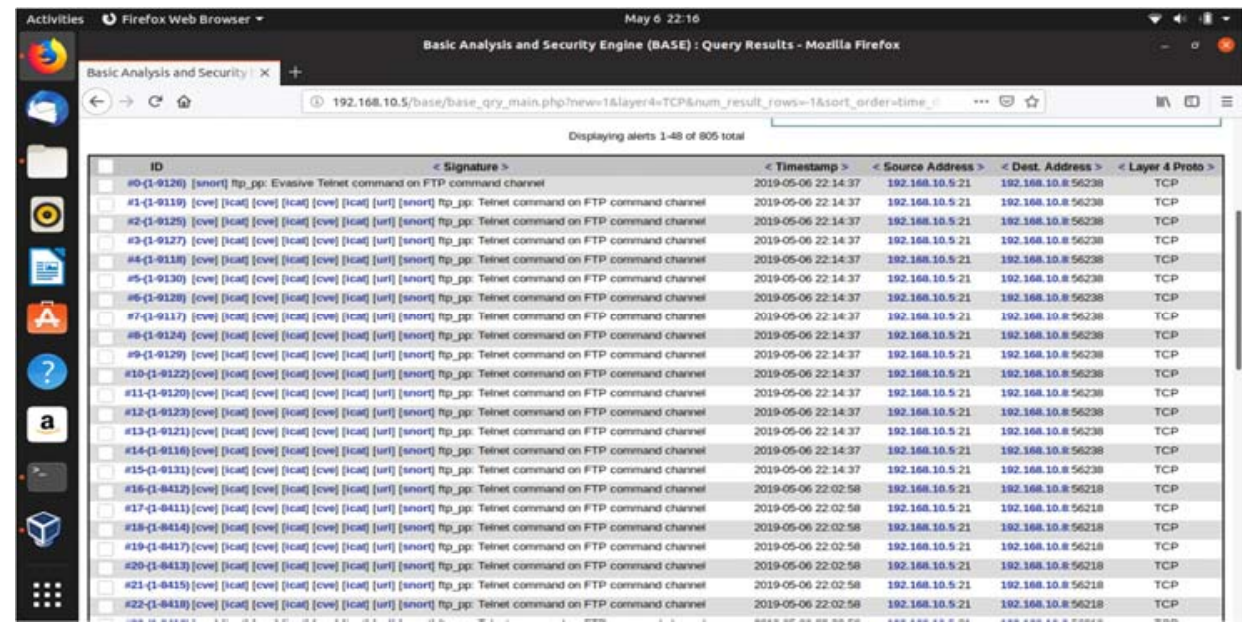

Gambar 11 Base Snort mengangkap aktifitas telnet.

Pada gambar 11 menjelaskan usaha telnet client/penyerang tetap tercatat pada base snort.

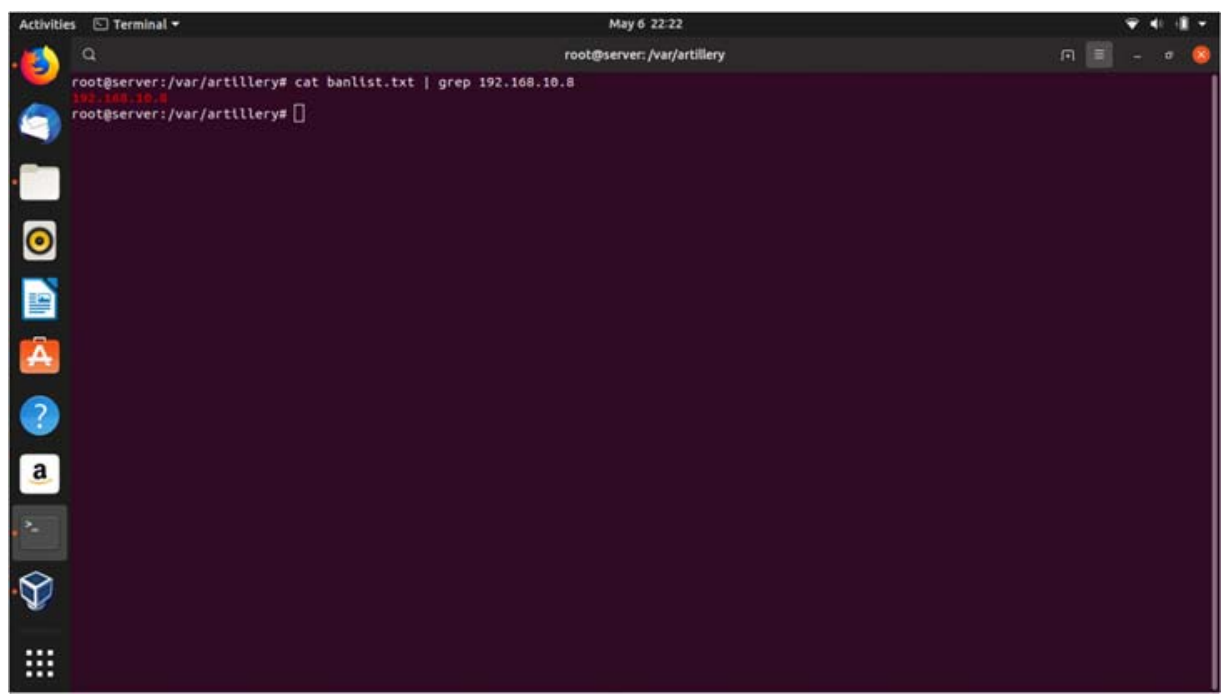

Gambar 12 IP Client/Penyerang yang terkena banned.

Pada gambar 12 terlihat IP Client/Penyerang tercatat di banlist Honeypot Artilery yang membuat penyerang tidak dapat melakukan koneksi ke server kembali.

Mengoptimalkan sistem keamanan jaringan yang dibuat dengan memonitoring dan memperbaruhi sistem keamanan jaringan yang telah dibuat dengan cara:

1. Artillery berbasis open-source sehingga dapat dikembangakan dengan menambahkan fungsi yang dapat disesuaikan dengan kebutuhan. 
AITI: Jurnal Teknologi Informasi

Volume 16 No. 2 Agustus 2019, 135-150

2. Melakukan update pada snort jika tersedia. Hal ini dimaksudkan agar database keamanan pada snort diperbaharui, sehingga jenis malware yang terbaru dapat dideteksi oleh snort.

3. Membuat akun di website : https://www.snort.org/ untuk mendapat notifikasi update rules terbaru dari snort.

4. Menambahkan tools keamanan jaringan yang kiranya bisa memperketat sistem keamanan pada jaringan.

5. Selalu melakukan apt-get updated dan upgrade OS Ubuntu agar sistem berjalan dengan baik dan mendapat versi sistem terbaru. Kiranya itulah beberapa cara dalam mengoptimalkan sistem keamanan jaringan yang telah dibuat, ini dimaksudkan agar sistem keamanan jaringan yang dibuat dapat mengikuti perkembangan jaman yang ada.

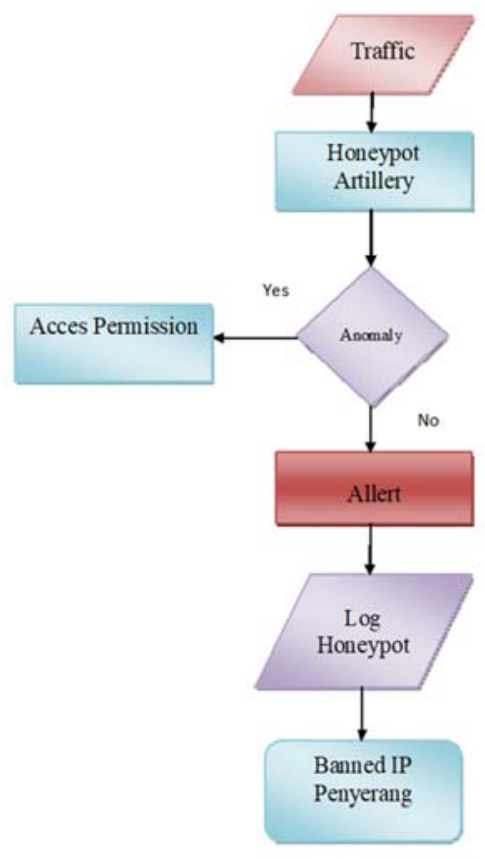

A. Diagram sistem Honeypot Artillery.

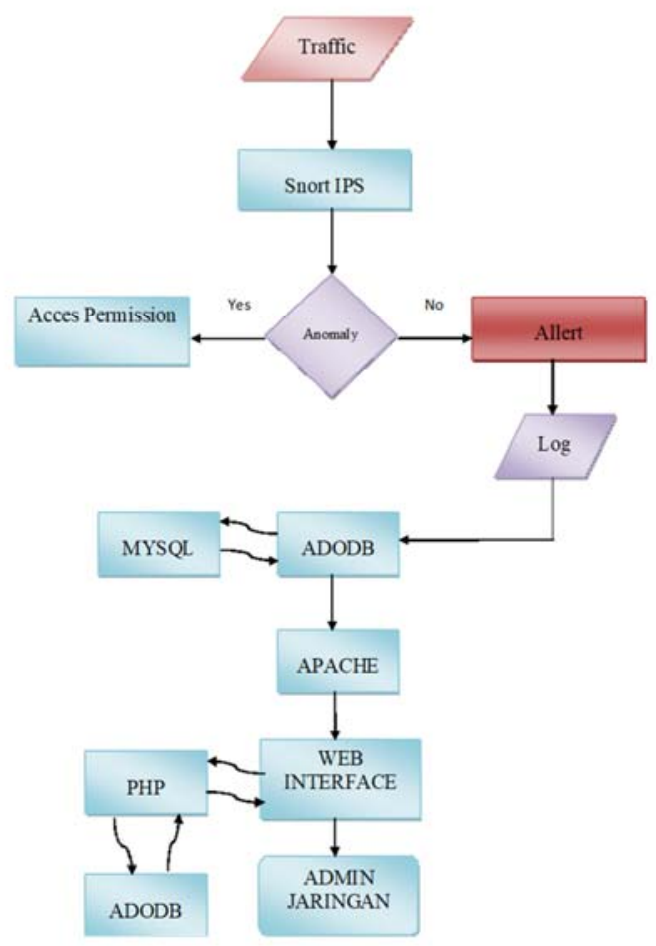

B. Diagram sistem Snort IPS.

Gambar 13 Diagram Sistem Honeypot Artillery dan Snort IPS

Gambar 13 menunjukan alur dari setiap sistem yang memiliki kekurangan masing-masing. Honeypot Artillery sendiri hanya dapat memblokir traffic yang masuk namun tidak dapat memberikan informasi tentang traffic yang masuk tersebut. Pada snort sendiri saat ada traffic yang masuk hanya memberikan 
Allert/peringatan tanpa ada tindakan lebih lanjut pada traffic tersebut namun snort dapat memberikan informasi tentang traffic tersebut yang ditampilkan di web interface.

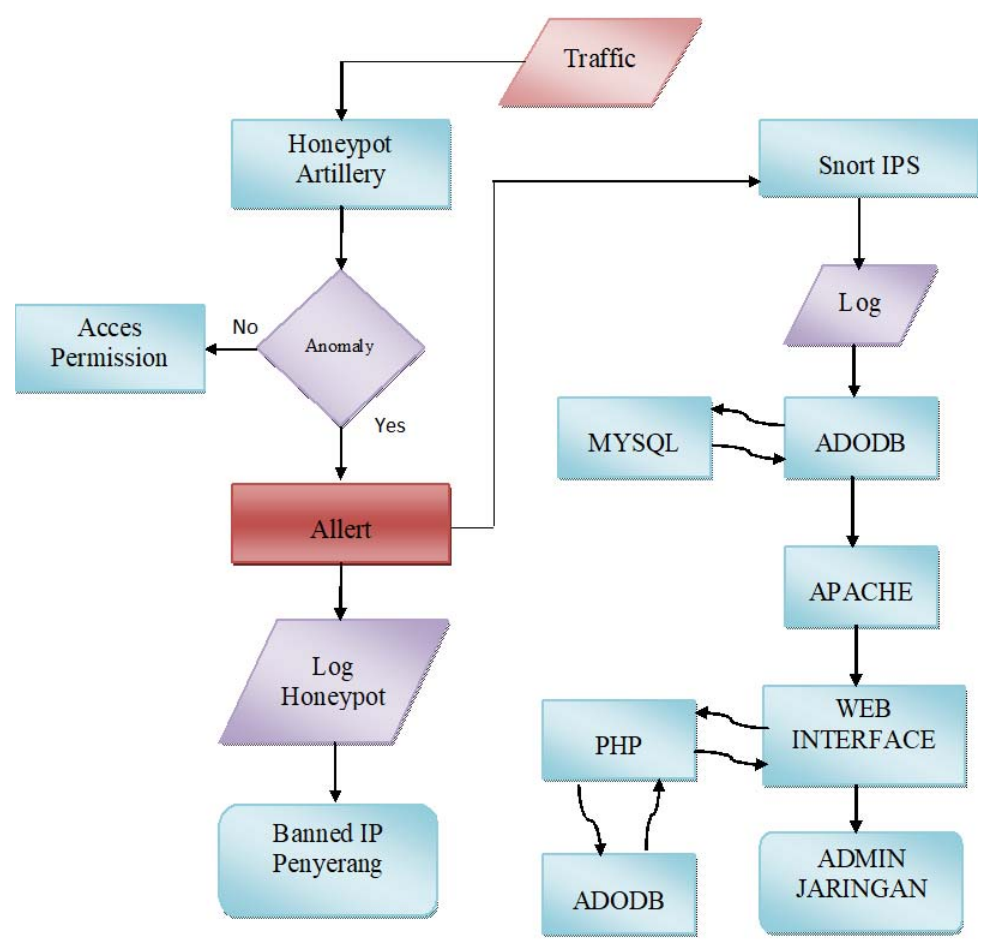

Gambar 14 Diagram penggabungan sistem Honeypot Artillery dan Snort IPS.

Gambar 14 menjelaskan setiap Traffic yang masuk ke dua sistem yang telah digabungkan akan langsung direspon dengan alur sistem. Saat trafic masuk ke sistem honeypot allert akan mencatat log dan juga kemudian allert dikirim ke Snort IPS untuk diproses melalui alur sistem Snort IPS kemudian akan di-input ke database namun sebelumnya Honeypot Artillery akan melakukan Banned IP Client/Penyerang.Data allert traffic nantinya akan ditampilkan ke web interface yang dapat dilihat admin jaringan untuk dianalisis. 
AITI: Jurnal Teknologi Informasi

Volume 16 No. 2 Agustus 2019, 135-150

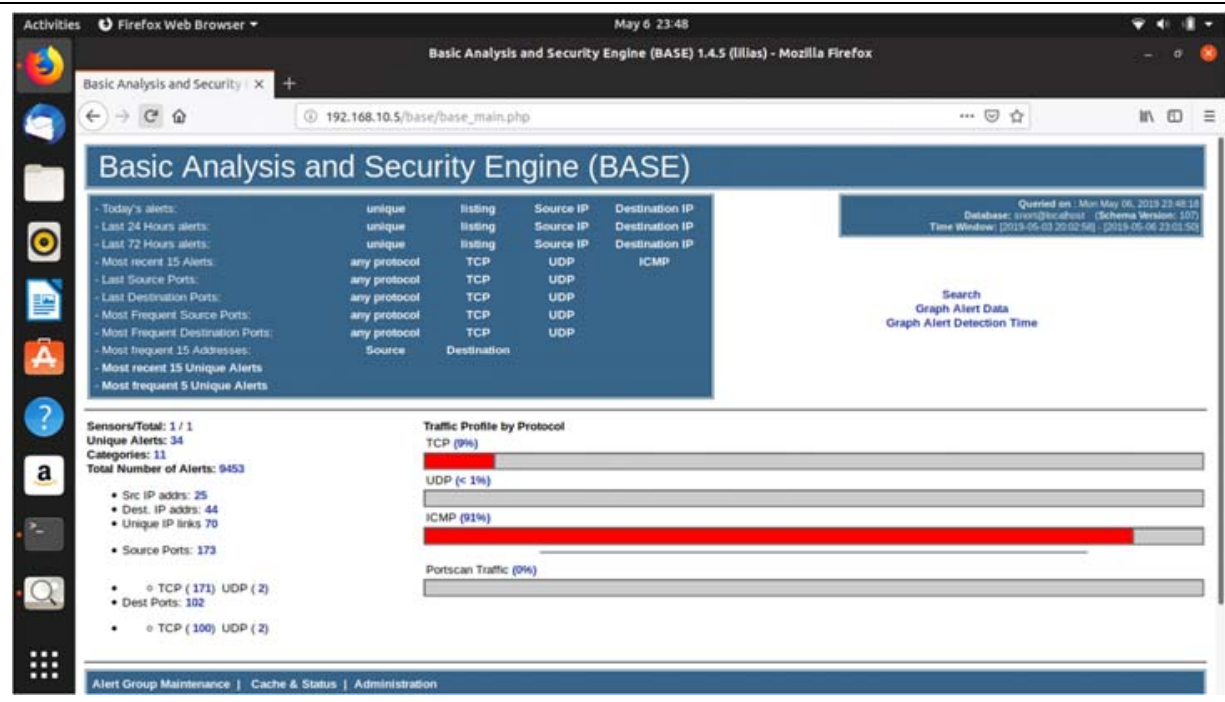

Gambar 15 Total Number of Allerts sebanyak 9453.

Gambar 15 menunjukan banyaknya Allerts yang tercatat di database sebanyak 9453 pada protokol TCP sebanyak 9\%, UDP sebanyak $<1 \%$, dan ICMP sebanyak $91 \%$.

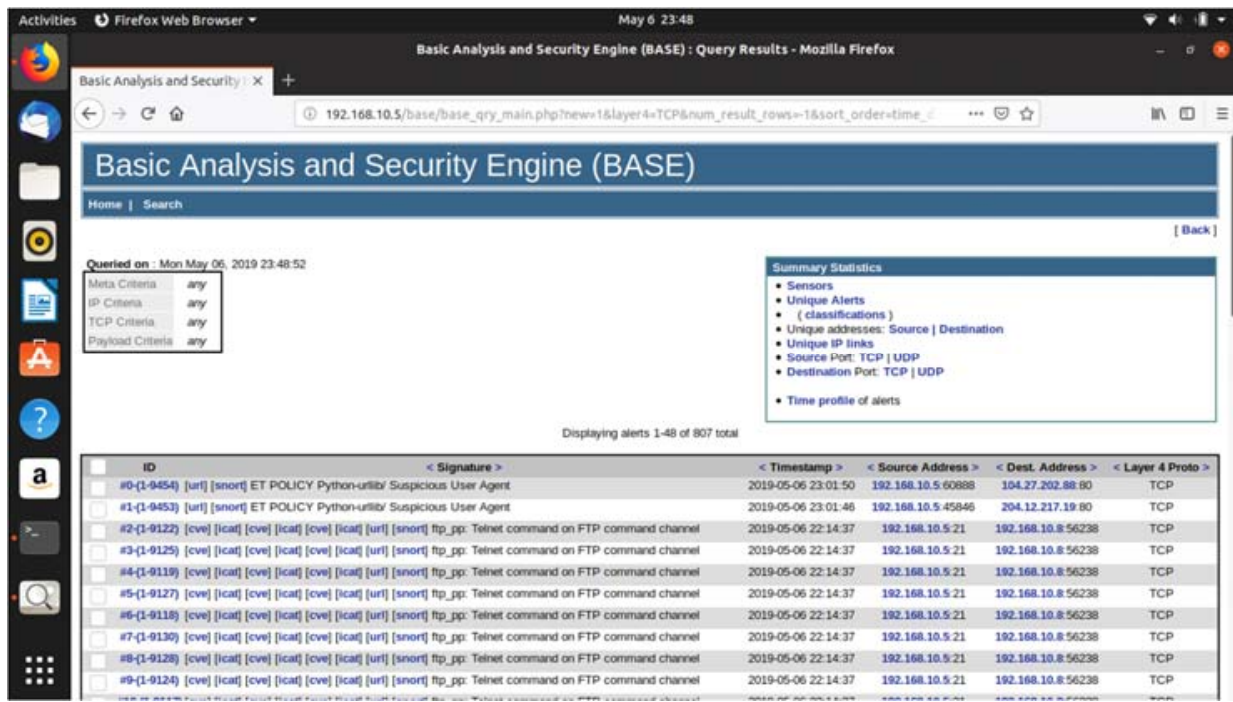

Gambar 16 Allert yang tercacat pada tabel TCP.

Gambar 16 menunjukan semua serangan yang menggunakan protokol TCP dicatat di tabel ini seperti pada simulasi yang telah dilakukan dan Allerts yang diperoleh sebanyak 807 Allerts. 


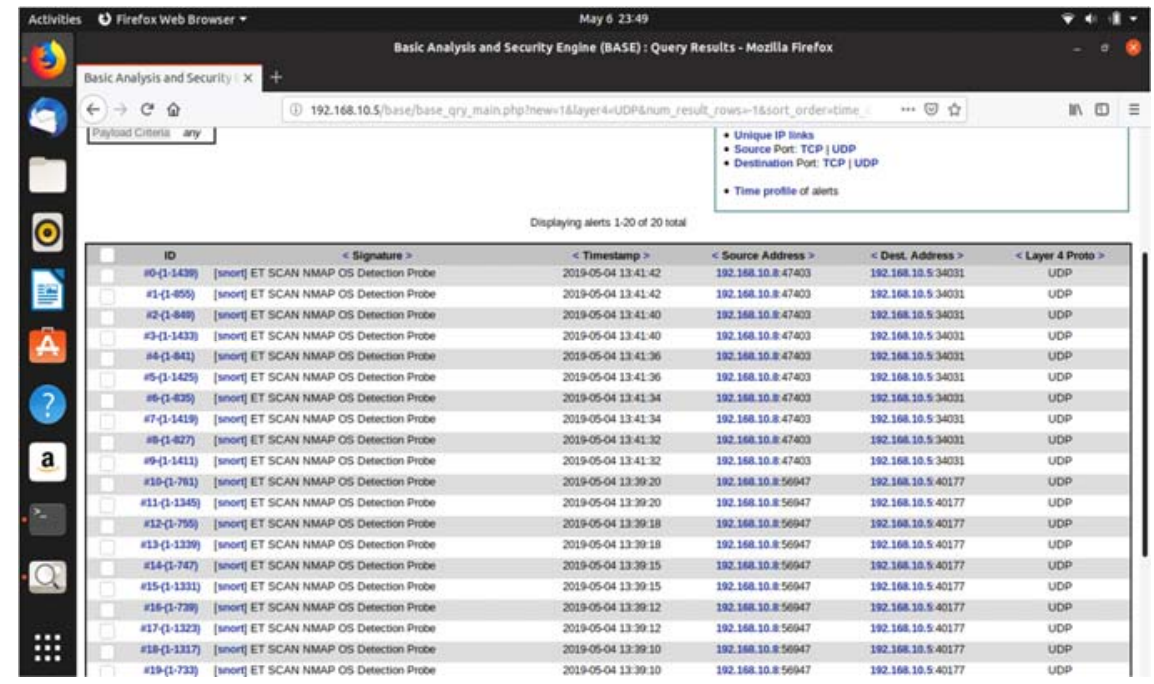

Gambar 17 Allert yang tercacat pada tabel UDP.

Gambar 17 pada saat dilakukan simulasi serangan scanning menggunakan NMAP Allerts yang dihasilkan tercatat di tabel UDP dan total serangan pada protokol UDP sebanyak 20 Allerts.

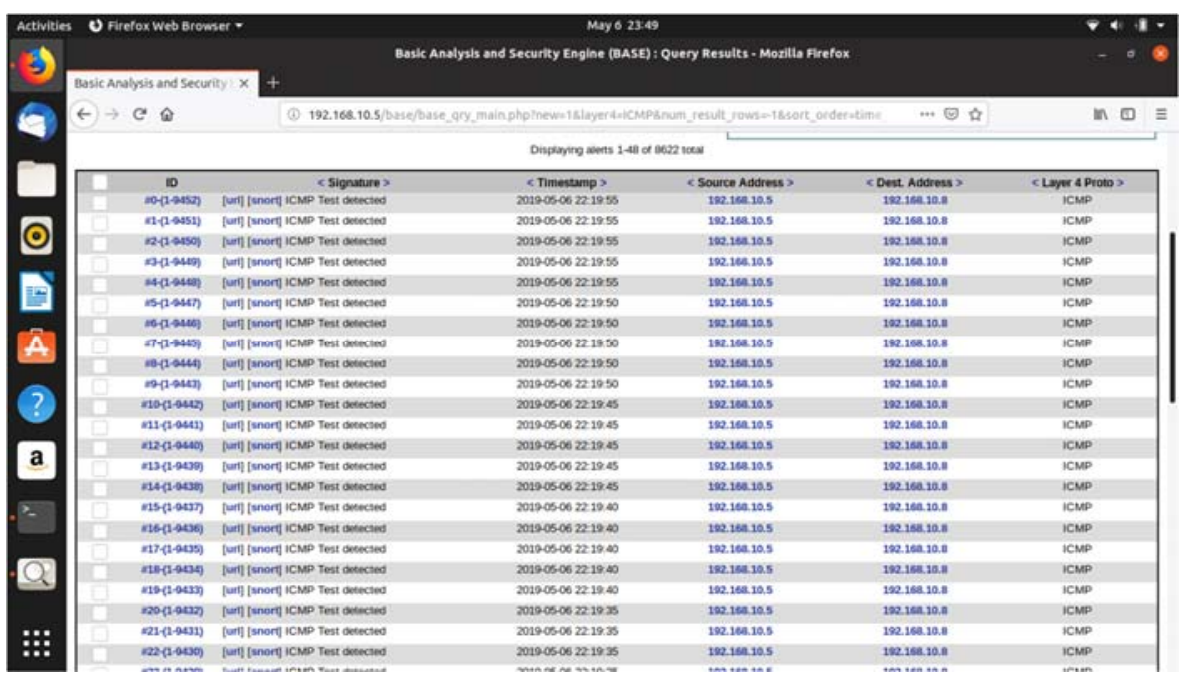

Gambar 18 Allert yang tercacat pada tabel ICMP.

Gambar 18 menunjukan Allerts pada tabel ICMP sebanyak 8622 karena setiap koneksi apapun ke server dicatat di tabel ini, seperti pada saat simulasi test ping ke server setiap koneksi dari penyerang ke server dicatat di kolom ini selama Client/Penyerang tidak memutuskan koneksi, Allerts pada tabel ICMP tidak akan berhenti mencatat Allerts. 
AITI: Jurnal Teknologi Informasi

Volume 16 No. 2 Agustus 2019, 135-150

Tabel 3 Kelebihan dan Kekurangan

\begin{tabular}{|c|c|}
\hline Kelebihan & Kekurangan \\
\hline $\begin{array}{l}\text { Akurat dan cepat karena Setiap allert yang } \\
\text { masuk langsung dicatat di database dan } \\
\text { lansung bisa dilihat statistiknya di BASE } \\
\text { page yang telah dibuat. }\end{array}$ & $\begin{array}{l}\text { Rule snort dan konfigurasi Honeypot } \\
\text { Artillery harus di-update atau } \\
\text { disesuaikan apabila ada pola serangan } \\
\text { baru, kemampuan untuk } \\
\text { pengamanan tergantung } \\
\text { pada rule/aturan yang } \\
\text { digunakan. }\end{array}$ \\
\hline $\begin{array}{l}\text { Dapat mengidentifiksi serangan dan } \\
\text { menyimpannya sebagai pola. }\end{array}$ & $\begin{array}{l}\text { Membutuhkan lebih banyak resource } \\
\text { untuk menganalisa } \\
\text { aktivitas. }\end{array}$ \\
\hline
\end{tabular}

\section{Simpulan}

Berdasarkan penelitian Simulasi Sistem Keamanan Jaringan penggabungan antara Snort IPS dengan sistem allerts-nya yang responsif dalam menangkap gangguan pada sistem Allerts yang tercatat di database sebanyak 9453 yang tediri pada Traffic Profile yaitu pada protokol TCP sebanyak 9\%, UDP sebanyak $<1 \%$, dan ICMP sebanyak 91\% dan Honeypot Artillery yang dapat mendeteksi 1 alamat IP (192.168.10.8) dari mesin virtual box yang dibuat dan melakukan Block IP tersebut sebelum memiliki kesempatan lagi untuk menyerang keseluruhan sistem.Sebelum dipasang Honeypot Artillery dan Snort IPS pada server tidak ada laporan atau data mengenai jenis koneksi apa saja dan dari mana saja koneksi tersebut berasal tanpa adanya proteksi lebih yang membuat tidak amanya server, dengan ini Honeypot Artillery dan Snort IPS dirasa cukup untuk mengamankan dan menganalisis pola serangan attackers yang ingin melakukan intrusi ke sistem jaringan komputer dan dengan memperhatikan kekurangan yang ada dapat membuat penggabungan dua sistem keamanan ini menjadi lebih baik lagi.

Adapun saran dalam penelitain ini yaitu bila diterapkan pada keamanan jaringan dapat ditingkatkan dengan menambahkan local rules pada snort sesuai dengan kebutuhan yang dibutuhkan dan mengupdate rule yang berasal dari website resmi snort.Meningkatkan performa Server dengan melakukan upgrade hardware.Dengan Honeypot Artillery berbasis open-source sehingga memudahkan Admin suatu jaringan untuk mengembangkan dengan menambahkan fungsi yang lebih baik lagi.

\section{Daftar Pustaka}

[1] BSSN.(2019,2 Februari).Langkah BSSN dalam melakukan deteksi ancaman siber , https://bssn.go.id/wp-content/uploads/2019/02/RilisForum-Cyber-Corner-Launching-Honeynet-Project-Revisi.pdf.

[2] B. . Octavian, Rancang Bangun Sort Base IPS. 2015. 
[3] T. A. Cahyanto, H. Oktavianto, and A. W. Royan, "Analisis Dan Implementasi Honeypot Menggunakan Dionaea Sebagai Penunjang Keamanan Jaringan,” J. Sist. Teknol. Inf. Indones., vol. 1, pp. 86-92, 2016.

[4] D. Ariyus, Internet Firewall. Yogyakarta: Graha Ilmu, 2006.

[5] P. L. Restanti, “Analisis Kolaborasi IDS Snort dan Honeypot,” pp. 1-27, 2014.

[6] F. Utdirartatmo, Trik Menjebak Hacker Dengan Honeypot. Yogyakarta: Andi, 2005.

[7] A. S. Nugroho, “Analisis Dan Implementasi Honeypot Menggunakan Honeyd Sebagai Alat Bantu Pengumpulan Informasi Aktivitas Serangan Pada Jaringan,” Inst. Sains Teknol. AKPRIND, 2013.

[8] Palcomtech.(2013,23 Desember). Metode Perancangan Jaringan dengan Model PPDIOO. http://www.news.palcomtech.com/metode perancangan jaringan-dengan-model-ppdioo/ 